\title{
Defining Hindustani Raga Musicians and Their Relative Intra-Statuses: An Analytical Study
}

\author{
Pragya Pyasi ${ }^{1}$ and Sanjoy Bandopadhyay ${ }^{2}$ \\ ${ }^{1}$ Assistant Professor, Department of Music, University of Hyderabad. \\ Email:pragya@uohyd.ac.in \\ 2Professor, Department of Music, Sikkim University. Email: sitardivine@gmail.com
}

\begin{abstract}
Two very widely used terms, 'musicians' and the 'musicians' statuses', are commonly applied labels across the music fraternity, where Hindustani Raga Music [HRM] is no exception. In HRM, there are no objectively laid definitions of these two expressions. In different music cultures, musicians' statuses were seen from the societal, economic, and based on the roles played in music production and rendering. The intra-status, a musicians' relative position within the same group, is not clearly defined. The formal texts of HRM also do not categorically define a musician. In India, Afghanistan, and Pakistan, people use the words vAggeyakAr, kalAvant, mirAsI, kasbi, AtAi, zauqI, and others, but these terms do not categorize musicians within the periphery of a specific musician's close circuit; these words do not point to intra-status. The current investigation used the DELPHI method to find some objective answers to defining musicians and their intrastatus. The HRM Experts from different parts of the world with an average HRM association of 39.11 years joined this investigation. The research exercise systematically generated an objective definition of HRM musician and suggested methods for defining HRM musicians' statuses.
\end{abstract}

Keywords: Musician, definition, status, Hindustani Raga Music

\section{Introduction}

We got stuck when we were pursuing our investigation to establish relationships between the Hindustani Raga Music [HRM], YouTube Video hits, Musicians' Status, and Music Patterns. We collected a considerable amount of data based on our subjective understandings of the Status of a Musician. After reaching a point, we realized that there is no clearly drawn definition for Music and Musician that satisfy the general understanding of today's HRM-associated population.

Sarangadeva, in his famous music treatise sangIt ratnAkara mentions the qualities and the three categories of composers termed as vAggeyakAra. The accepted combinations of excellent voice quality, attitude, virtuosity, lineage and repertoire were the deciding factors to put a person under the $v$ AggeyakAr category (Sarangadeva, Chap.3, Sloka 2-11). The treatise further describes the merits and demerits of gAyaka, the vocalists, and vAdaka, the instrumentalists. Sarangadeva written list of the merits of musicians can be split into three categories; audio, visual, and attitude. The audio features include the voice quality and repertoire; visible components have gestures, the musician's appearance, it also talks about mindset and finally the avoidance of all the qualities listed under the demerits (Sarangadeva, Chap. 3, Sloka 13-38, 1976, Sarangadeva, Chap. 6, Sloka 1215-1219, 1986). All

(c) AesthetixMS 2021. This Open Access article is published under a Creative Commons Attribution Non-Commercial 4.0 International License (http://creativecommons.org/licenses/by-nc/4.o/), which permits non-commercial re-use, distribution, and reproduction in any medium, provided the original work is properly cited. For citation use the DOI. For commercial re-use, please contact editor@rupkatha.com. 
these components lead us to good and bad musicians without any clear indication towards scaling methods.

Why the music fraternity consider a musician a higher status musician than another musician is a question that requires systematic inquiry. As there are no definite parameters to put a musician under different relative statuses, subjective arguments on this topic are pretty run-of-the-mill. The music lovers participate in active debates like the football fans get involved in disputes on football teams and players. During the second half of the twentieth century, Ravi Shankar and Vilayet Khan's intra-status conflict was a hot topic among HRM lovers. Interestingly, most of these ruckuses used to base on subjective opinions and assessments without many references.

This research aims at creating some missing basic pointers and determine them objectively. This project focuses on generating the definition of a Hindustani Raga Musician and the intra-statuses of these musicians. The systematically produced research outputs should successfully work as tools in the required areas of future researches on Hindustani Raga Music.

\subsection{Notions for Musicians' statuses in India}

Looking at the changes in Hindustani Raga Music during the last few hundred years, the changes in notions were quite obvious. In the Indian socio musical context, the Musician's status is as essential as the music itself. The quality of music is judged according to popularity and seniority retained by the artist. The age, reputation of the $\operatorname{ghar} A n A$, and the artist's high market values establish an artist's seniority. Although age is the essential criterion to respect older persons in Indian society, some other measures assess the seniority status in socio musical hierarchies. Performers like Kaushiki Chakraborty, Niladri Kumar may be younger but enjoy a higher community position than several older artists. Napier says,

"There are several other criteria for seniority that may or may not correspond with age. Reflecting some extent the same closeness to the greater past that characterizes older artists, younger artists may be considered senior by being associated with central figures of a particular gharana or certain highly respected artists of an earlier generation. Similarly, knowledge of a large number of compositions, and acknowledged thoroughness of training may impart seniority" (Napier, 2011).

People show reverence to veterans and elderly artists. But it is much relevant that an artist younger in age, possessing extraordinary musical talent and high virtuosity levels, relish equal standards for the status as a senior artist. It is subjective and should depend on the audience's interpretation to rank an artist's authority based on his musical creation's quality regardless of age or heredity. Contextually, heredity is a substantial criterion for the identification and establishment of a musician in society. In raga music, the discriminatory status between the soloist and accompanists was profusely present. There used to be a considerable difference in the economic standards. Earlier studies mention that musicians' position based on their roles as Soloist and Accompanists in music renderings was considered significant for their professional existence and socio-economic standards (Neuman, 1980). Clayton discussed the conflicts and contestations between these two (Clayton \& Leante, 2015). When seniority by age has its importance in determining superiority, the lineage of musician and the artist's vast musical acquisitions may lead to a higher fraternity status. 


\subsection{Musicians' status in different cultures}

Different statuses of traditional musicians in Pakistan and Afghan societies are built upon their positioning as hereditary and nonhereditary musicians. These are mainly mIrAsI, kalAvant, and dhAri (Lybarger, 2011; Neuman, 1980). A person proficient in music is a kalAvant. All professional musicians belong to the mirAsI group, where further bifurcation is there as kasbi for the hereditary musicians and at $A i$ for all nonhereditary musicians. In Afghanistan, zauqI replaced the term at $A i$ and indicates the music-amateurs. Although amateur musicians rarely receive the status of successful professional musicians from the music connoisseurs, the amateur musicians zauqI are considered more respected than the professional musicians kasbi in Afghanistan (Baily, 1979).

Good amateur musicians can be equally serious about their riyAz like their counterpart professionals. These dabblers also pay for receiving training and perform in popular music festivals (Juniu et al., 1996). An excellent example of such an amateur was Radhika Mohan Maitra. Maitra was a well-recognized name with outstanding performance records. RMM was a name even when two colossal pillars in sarod playing Allauddin Khan and Hafiz Ali Khan were shining like mid-day Sun in Hindustani Raga Music.

A fascinating study in 1966 predicted that Jazz Musicians' positioning would be lower than the Commercial Musicians in the broader community, and the opposite will be valid within the Jazz community (Stebbins, 1966). It appears to be similarly true here in India too. Commercial Music or Bollywood music or filmI gAne do not receive high status, even viewed as low within the Raga Music practitioners and lovers circuit, when Bollywood music's popularity in the larger space is at astronomical heights.

\subsection{The Music and its current status}

The old treatizes of Indian Music describe sangIta as combined art-creations with singing, instrumentation, and dancing elements. Today's rAga music does not commonly include dance elements excepting some rare experimentations lately. What we experience are primarily vocal or instrumental renderings with rhythm and drone supports. We also witness some presentations where vocalists, melody-instrumentalists, and rhythm artists join in musical ventures. Inter-genre Music is also becoming very popular where a Hindustani Raga Musician joins a Ghazal singer or a Sufi Singer and elaborate on some very famous HRM vocal composition. We enjoy inter-stylization in Indian Music; we listen to commendable raga elaborations jointly in Carnatic and Hindustani styles. The HR musicians, Carnatic musicians, and rhythm artists from both styles join together in such inter-stylized music-making. The concert organized in Dubai, and the video uploaded on YT on January 28, 2020, shows more than 1.6 million views after 15 months (Srishti LIVE, 2020). In this video, these two musicians sang the famous thumri yAd piyA ki Aye popularized by the old music legend Bade Ghulam Ali Khan during the first half of the $2 \mathrm{O}^{\text {th }}$ century. The same duo rendered the famous Carnatic composition kriSnA nI begAne bAro composed by Vyasatirtha, a 15th-century composer, in another video. The video attracted about a million viewers during the first 49 months of its online presence (SURER ANTARALE, 2017).

\section{Methodology}

The present research study mainly opted for e-DELPHI to define Hindustani Raga Musicians and their relative statuses. The research has two parts, namely, 1. Defining a Hindustani Raga Musician, 
and 2. To categorically define the musicians, as per the received definition from part 1 of the exercise, relative statuses.

\subsection{Briefly on DELPHI Method}

In music studies, the application of the DELPHI method is rare. However, the researchers showed that the DELPHI method was a potential tool for generating answers to some primary theoretical areas of HRM, e.g., defining a musician or ascertaining intra-statuses of musicians are yet to be determined with clarity.

This DELPHI method puts in efforts on generating consensus of the experts of the related field. The method takes several steps to reach its finals. DELPHI first identifies a good number of experts who can support in contriving the answer. Then it goes for several rounds of Q-A sessions to reach the consensus of the experts. The first round usually run with mostly open-ended questions to generate different options against the problem. Then it starts working on close-ended questions based on the data generated in the first round. Several rounds of DELPHI may run to reach the consensus of the experts. Different researchers took different percentages of agreements by the experts as consensus. The experts' attainments of agreement can be accepted as consensus varies from $51 \%$ to $80 \%$.

\subsection{DELPHI in this research project}

The investigation opted for two sets of Delphi; SET-A and SET-B. Set-A had primarily open-ended questions to the experts. The researchers framed questions for Set-B based on the detailed analysis of the answers received through DELPHI Set-A. This Set-B mostly contained close-ended questions. The project used Google Forms for the distribution of the questions and receiving the experts' feedback. The research focus was on retaining objectivity. The collected data was analyzed using statistical treatments; the study used the Likert scale.

Stage 1 of the project was to determine experts for this project. So, the investigators decided to have experts who have at least 20 years of association with HRM and are significantly involved with Music. They also agreed that the study would accept decisions that receive verdicts of $70 \%$ or more experts. It is good to record that many DELPHI studies consider $51 \%$ agreement among experts as reaching consensus (Loughlin \& Moore, 1979).

The researchers initially approached 160 experts; among these experts, 96 experts responded to DELPHI SET-A. The laid norms could accept 90 submissions as the rest of the recommendations came from people with less than 20 years of association with HRM. The project received professional musicians, university professors, acclaimed researchers, music teachers, and others. Some experts declared themselves perennial students, instrument makers, organizers, amateur musicians, musicologists, and researchers. In the SET-B, the project received verdicts from 74 experts ${ }^{1}$. We obtained the responses on a 5-point Likert scale. All the received inputs were passed through frequency analysis for results and interpretations.

The study was intermittently conducted in late 2020 .

\footnotetext{
${ }^{1}$ See Appendix.
} 
5 | Defining Hindustani Raga Musicians and Their Relative Intra-Statuses: An Analytical Study

\subsection{Participant Experts for the study}

The average years of association of the experts with Hindustani Raga Music, who participated in both the DELPHI SET-A and SET-B operations, was 39.11 years. The study obtained opinions from experts between 20 and 67 years of association with HRM. The following Chart-1 is showing the 'frequency' and 'years of association' distribution.

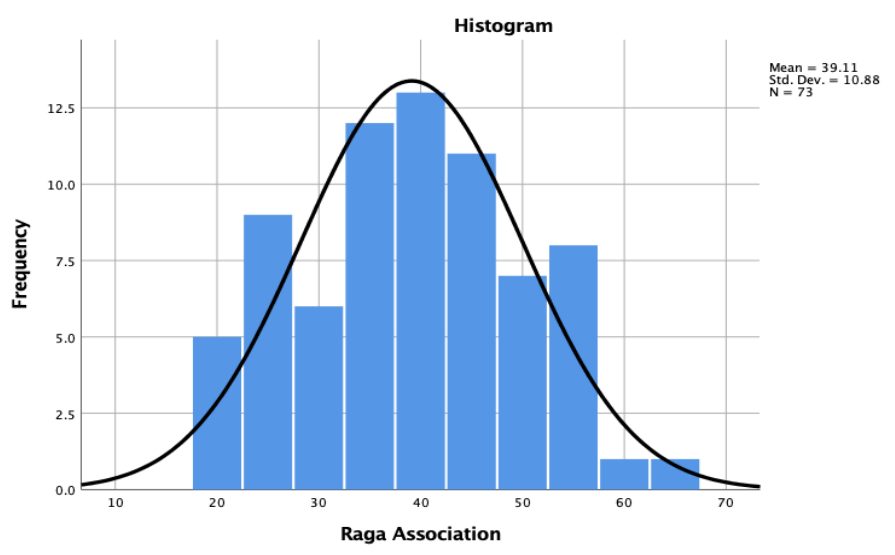

Chart 1

\begin{tabular}{|l|l|r|}
\hline \multicolumn{2}{|c|}{ Raga Association [Years] } \\
\hline $\mathrm{N}$ & Valid & 73 \\
\cline { 2 - 3 } & Missing & 0 \\
\hline Mean & 39.11 \\
\hline Median & 40.00 \\
\hline Mode & 40 \\
\hline Minimum & 20 \\
\hline Maximum & 67 \\
\hline
\end{tabular}

Table 1

The median and mode for 'years of association with HRM' was 40 years and Std. Dev. 10.88. The table-1 tells the status of the participating experts.

The study was intermittently conducted during the second quarter of 2020 and early 2021. 


\section{A. Results - Part I}

\section{A.1. Definition of Musician based on Delphi Set-A and validated by Set-B}

The DELPHI Set-A operation gave the following description for a musician; "A person with a good repertoire in Hindustani Raga Music [HRM] and who can impress the audiences with Hindustani Raga renderings may be defined as a Hindustani Raga Musician."

The above definition was strongly validated through DELPHI Set-B operations. The Delphi Set-B operation gave the following result.

\begin{tabular}{|c|c|c|c|c|c|c|c|}
\hline & & \multicolumn{5}{|c|}{ Defining Musician based on Delphi-I } & \multirow[t]{2}{*}{ Tota } \\
\hline & & $\begin{array}{r}\text { Fully } \\
\text { Disagree }\end{array}$ & $\begin{array}{r}\text { Disagre } \\
\mathrm{e}\end{array}$ & $\begin{array}{r}\text { Nor Agree } \\
\text { nor } \\
\text { Disagree }\end{array}$ & $\begin{array}{r}\text { Generally } \\
\text { Agree }\end{array}$ & $\begin{array}{r}\text { Fully } \\
\text { Agree }\end{array}$ & \\
\hline \multirow{3}{*}{$\begin{array}{l}\text { Raga } \\
\text { Association } \\
\text { Years }\end{array}$} & $20-35$ & 3 & 1 & 1 & 11 & 6 & 22 \\
\hline & $35-50$ & 1 & 1 & 3 & 16 & 13 & 34 \\
\hline & $50+$ & 1 & o & 1 & 11 & 4 & 17 \\
\hline \multicolumn{2}{|l|}{ Total } & 5 & 2 & 5 & 38 & 23 & 73 \\
\hline
\end{tabular}

Table 2

The definition was fully agreed upon by $31.51 \%$ experts and generally agreed upon by $52.05 \%$ experts. So the total $83.56 \%$ experts recorded their agreement on the definition. As the percentage of experts is more than $70 \%$, this definition was accepted.

\section{A.2. Other significant characteristics in a Hindustani Raga Musicians}

In Delphi SET-A, the experts pointed out some important qualities required to be a musician. SETA opened up a new focus towards qualities like Spirituality, Transcending listeners, Professional Attitude, Originality in Music, to be a teacher, etc.

We designed DELPHI SET-B to address these new points. So, we floated SET-B to 90 experts whose answers were considered to analyze SET-A inputs.

- The Music and its practices should have a Spiritual approach

- The musicians' Music should able to transcend the listeners.

- The musicians should present Music that has originalities.

- The musicians should be teachers by themselves.

The spiritual approach here indicates the musicians connecting their Music with spirituality, an attitude where Music is a tool to connect with the supreme being. Transcending listeners with the musical impacts means the listeners' mental journey from the normal state to an elevated state of mind. Originalities in HRM renderings refer to the musical elements that are significantly different 
from earlier widely-performed musical elements. Most of the musicians, including the master musicians, teach Music to maintain their legacy. So, the musicians become teachers too.

The results show that the following percentages of experts understand the qualities as necessary.

\begin{tabular}{|l|r|}
\hline Qualities & Experts' support \\
\hline Originalities & $89 \%$ \\
\hline Transcending Listeners & $84 \%$ \\
\hline Spirituality & $66 \%$ \\
\hline Professional Attitude & $61 \%$ \\
\hline Teachers by themselves & $32 \%$ \\
\hline
\end{tabular}

Table 3

Being scored $70 \%$ or more, Originalities received the highest importance with $89 \%$, and the 'Ability to transcend listeners with Music' received $84 \%$. These are the qualities that DELPHI Technique endorsed to be taken as important qualities in a musician.

\section{A.2.1. Importance of the presence of originalities}

Let us also look at the detailed frequency analysis for the quality 'Originality.'

\begin{tabular}{|c|c|c|c|c|c|}
\hline \multicolumn{6}{|c|}{ Presence of Originalities } \\
\hline & & Frequency & $\begin{array}{r}\text { Per } \\
\text { cent }\end{array}$ & $\begin{array}{r}\text { Valid } \\
\text { Percent }\end{array}$ & $\begin{array}{r}\text { Cumulative } \\
\text { Percent }\end{array}$ \\
\hline \multirow[t]{5}{*}{ Valid } & Very Unimportant & 4 & $5 \cdot 5$ & $5 \cdot 5$ & $5 \cdot 5$ \\
\hline & $\begin{array}{r}\text { Nor important nor } \\
\text { unimportant }\end{array}$ & 3 & 4.1 & 4.1 & 9.6 \\
\hline & Important & 27 & 37.0 & 37.0 & 46.6 \\
\hline & Very Important & 39 & 53.4 & 53.4 & 100.0 \\
\hline & Total & 73 & 100.0 & 100.0 & \\
\hline
\end{tabular}

Table 4

Interestingly, $53.4 \%$ of the expert population [ $\mathrm{N}=73$ ] identified Originalities as a Very Important component in a musician when 37\% experts indicated as Important. 4.1\% of experts thought this quality was not important nor unimportant, and 5.5\% consider this as 'Very Unimportant.' No expert put Originalities under 'Unimportant' category. 


\section{A.2.2. Importance of Transcending Listeners}

To analyze the importance of the Ability of rendered Music to transcend its listeners, let us bring forward the detailed frequency analysis of the experts' verdicts when $\mathrm{N}=73$.

\begin{tabular}{|c|c|c|c|c|c|}
\hline \multicolumn{6}{|c|}{ Transcend listeners } \\
\hline & & Frequency & $\begin{array}{r}\text { Per } \\
\text { cent }\end{array}$ & $\begin{array}{r}\text { Valid } \\
\text { Percent }\end{array}$ & $\begin{array}{r}\text { Cumulativ } \\
\text { e Percent }\end{array}$ \\
\hline \multirow{5}{*}{$\begin{array}{r}\text { Vali } \\
\mathrm{d}\end{array}$} & Very Unimportant & 2 & 2.7 & 2.7 & 2.7 \\
\hline & $\begin{array}{l}\text { Nor important nor } \\
\text { unimportant }\end{array}$ & 5 & 6.8 & 6.8 & 9.6 \\
\hline & Important & 35 & $47 \cdot 9$ & $47 \cdot 9$ & $57 \cdot 5$ \\
\hline & Very Important & 31 & 42.5 & 42.5 & 100.0 \\
\hline & Total & 73 & 100.0 & 100.0 & \\
\hline
\end{tabular}

Table 5

From Table- 5 , the data reveals that that $42.5 \%$ of experts think the 'Ability to transcend listeners through Music' as 'Very Important,' and $47.9 \%$ 'Important.' This trend is opposite to the importance distribution of 'Originalities.' For 'Originalities,' a higher percentage of experts thought it Very Important [53.4\%, 37\%] when in Transcending lesser percentage of experts consider this very important $[42.5 \%, 47.9 \%]$. The comparative results show that Originality in Music is a vital component for a musician, and the 'Ability to Transcend the listeners' an important component.

\section{A.2.3. Summing up the results}

From the detailed analysis and the obtained results, the experts agreed that a musician might be; A person with a good repertoire in Hindustani rAga Music [HRM] and who can impress the audiences with Hindustani rAga renderings may be defined as a Hindustani rAga Musician. The Music produced by the musicians must present originalities and transcend the audiences.

\section{B. Results - Part - II}

DELPHI operations were conducted to define the statuses of Hindustani Raga Musicians objectively. The proposal was to ascertain an HR musician's standing based on the Musician's 'age and fame'. The proposal included special age-cushions for exceptionally famous musicians. A very high fame musician may receive a cushioning, say of 5 years, and put to a higher status. Let us assume that the musicians below 35 years of age will be taken as Young Musicians. Similarly, musicians of the age group 35 to 60 years may be taken as Contemporary Musicians, 6o to 90 years as Senior Musicians, and 90 years and above as Very Senior Musicians. A very famous or super-star may receive five years of age cushioning in such divisions. A super-star musician aged between 30 to 35 may receive the status of Contemporary Musician when the minimum age for a Contemporary 
Musician was set as 35 years. Similarly, a very famous musician between 55 and 60 can be considered a Senior Musician, when the minimum set age was 60 years.

The present DELPHI exercise could not attain $70 \%$ acceptance of the proposed parameters, and the picture of agreement, neutrality and disagreement are as below:

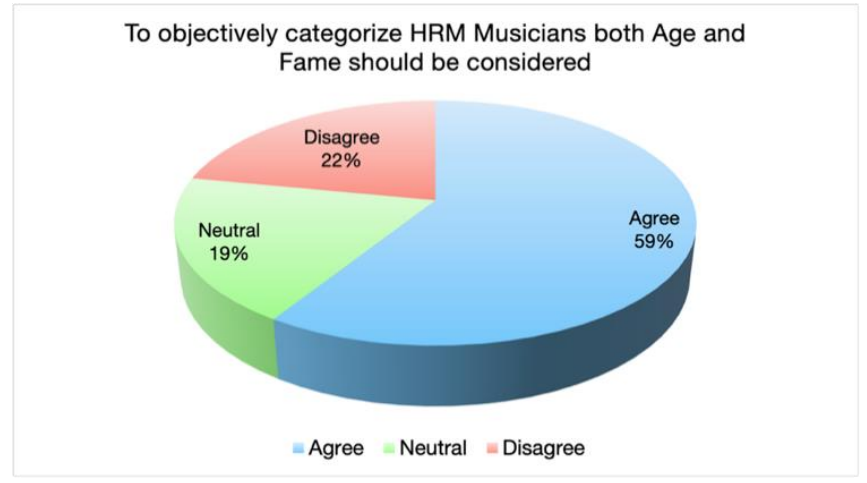

Chart-2

The above chart shows that $59 \%$ of experts agreed to assign musicians' status based on age and fame. This group include both completely agree and generally agree. $19 \%$ of the experts remained neutral, and $\mathbf{2 2} \%$ disagreed. The experts shown under disagree category comprise the experts who typically and completely disagree [Chart-2]. The difference between the agreed experts and disagreed experts was $37 \%$ of the total count $\mathrm{N}=73$. The agreeing experts' count was $59 \%$ and therefore below $70 \%$.

During the process, DELPHI also threw open-ended questions. These open-ended questions aimed to obtain some directions through which the investigation may define different statuses of musicians objectively. But, none of the received suggestion could lead towards objectively defining the statuses and therefore not accepted.

\section{Discussions}

\subsection{Defining the Hindustani Raga Musicians}

The effort to objectively define a Hindustani Raga Musician through the Delphi method inducted experts from different Hindustani Raga Music fraternity sectors. The idea was to generate opinions that can represent the collective opinions of the HRM fraternity. Therefore the generated results can be accepted as the depiction of the insights of the HR population.

While defining Hindustani Raga Musicians, the identified qualities of musicians in the research clearly showed that the experts gave higher importance to the quality of music and their good impacts on the audiences. Originality in Music was accepted as an essential factor. The experts emphasized that new musical ideas and concepts generate effectivity in music and play a critical role. This approach indicates that a high level of musicianship emerges when original Music impresses the audiences and transcends them. 


\subsection{Defining the musicians' statuses}

The research project was an exercise to originate some well-grounded theory on Hindustani Raga Musicians' status. The DELPHI method could successfully generate an expert agreement level of $59 \%$. So, the achieved agreement level is more than $51 \%$.

Taking $70 \%$ of positive responses from the experts as consensus, the proposal of deriving HR musicians' status based on age and fame failed to get ascertained. However, there are examples that $51 \%$ or more agreement is accepted as the consensus of the experts, "In keeping with most other Delphi studies, consensus was defined as 51 percent agreement among respondents" (Loughlin \& Moore, 1979). Accepting the $51 \%$ agreement as experts' consensus, the achieved agreement responses $59 \%$ is considerably high and may be considered the experts' consensus.

\section{Conclusion}

The research brought out the definition of Musicians and objectively defined the parameters to determine the intra-statuses of musicians. These are the two basic terms used widely in musicrelated investigations. The present research findings are expected to help future research where Music, Musicians, Musicians' Status, or Musicians' roles are considered research components. The policymakers may also like to use the current research outputs in formulating policies relating to the different status of HR Musicians. As the experts in this Delphi research belong to the various strata of the HRM society, they represent the HRM population. The effective dissemination of the present research findings is expected to help the HRM fraternity with better harmony and lesser conflicts.

\section{Acknowledgements}

The authors heartily acknowledge Professor Abhijit Dutta's support for his suggesting the Delphi Method for this investigation.

\section{References}

Sarangadeva. (1976). Sangeet Ratnakar (Vol. II). (S. S. Shastri, Ed.) Adyar, Madras, India: The Vasanta Press, The Theosophical Society.

Sarangadeva. (1986). Sangeet ratnakara (Vol. III). (S. S. Shastri, Ed.) Adyar, Madras, Madras, India: The Vasanta Press, The Theosophical Society.

Baily, J. (1979). Professional and Amateur Musicians in Afghanistan. In The World of Music (Vol. 21, Issue 2, pp. 46-64). Verlag für Wissenschaft und Bildung. https://www.jstor.org/stable/43560606

Clayton, M., \& Leante, L. (2015). Role, status and hierarchy in the performance of North Indian classical music. Ethnomusicology Forum, 24(3), 414-442. https://doi.org/10.108o/17411912.2015.1091272

Juniu, S., Tedrick, T., \& Boyd, R. (1996). Leisure or work?: Amateur and professional musicians' perception of rehearsal and performance. Journal of Leisure Research, 28(1), 44-56.

https://doi.org/10.108o/o0222216.1996.1194976o 
Loughlin, K. G., \& Moore, L. F. (1979). Using Delphi to achieve congruent objectives and activities in a pediatrics department. In Academic Medicine (Vol. 54, Issue 2, pp. 101-106).

https://doi.org/10.1097/oooo1888-197902000-00006

Lybarger, L. H. (2011). Hereditary Musician Groups of Pakistani Punjab. Journal of Punjab Studies, 18(1/2), 97-129.

Napier, J. (2011). Re-organization and Rhetoric: Changes in the social organization of North Indian classical music. Musicology Australia, 27(1), 35-53. https://doi.org/10.1080/o8145857.2005.10416522

Neuman, D. M. (1980). The Life of Music in North India (p. 296). Manohar.

Stebbins, R. A. (1966). Class, Status, and Power among Jazz and Commercial Musicians'. https://www.jstor.org/stable/4104854

Srishti LIVE. (2020, June 28). Yaad Piya Ki Aaye | Jugalbandi | Ustad Rashid Khan | Hariharan. https://www.youtube.com/watch?v=DtMKglTru74

SURER ANTARALE. (2017, February 10). Here's a glimpse of Hariharan and Ustad Rashid Khan's stunning performance at Bangalore. https://www.youtube.com/watch?v=dU1lx2xcRto

\section{Appendix A}

List of experts who participated in both DELPHI Set A and Set B and did not prefer to remain anonymous.

Abhijit Banerjee, Amit Kumar Verma, Anindya Banerjee, Aniruddha Arvind Joshi, Anaya Milind Thatte, Anjali Sharma, Archana Madhav Ambhore, Aranyakumar Munenni, Ashis Chakraborty, Asit Kumar De, Asit Roy, Basavi Mukerji, Biswajit Sahu, Chandrima Majumdar, Daniel Neuman, Dipankar Mukherjee, Diwakar Kashyap, Eshita Chakraborty, George Ruckert, Himanshu Vishwaroop, Indranil Mallick, Isuru Dayantha Kondasinghe, Jonathan Roy Barlow, Jayadas R, Jayant Narhar Khot, Joep Bor, Kannan Sankaran, Lakshmi Subramanian, Lalit Mohant, Likeshwar Verma, Luva Nahid Choudhury, Mallika Banerjee, Manali Ghosh, Manas Vishwaroop, Meena Banerjee, Mita Nag, Parimal Chakrabarty, Parth Chakraborty, Partha Bose, Pavani D, Pintu Saha, Prateek Chaudhuri, Praveen Sheolikar, Rajesh Shah, Rajrupa Chowdhury, Rajyasree Ghosh, Rakhi Banerjee, Ramprapanna Bhattacharya, Rantideb Maitra, Ravi Sharma, Saswata Roy, Sabyasachi Sarkhel, Samir Chatterjee, Sandipan Samajpati, Sanjay Kumar Verma, Sangeeta Pandit, Santosh Kumar, Shailaja Khanna, Sougata Roy Chowdhury, Sukanya Mukherjee, Suneera Kasliwal Vyas, Suranjita Paul, Swarna Khuntia, Tripti Watwe, Troilee Dutta, Varsha Agrawal, Vivek Agnihotri. 